
D:\Nsurg\Vol. 24, No. 1, Jan. - Mar., 2020\Nsurg-10.Doc
Fig. 1-5 Color
(A)
P. $67-72$
III

ORIGINAL ARTICLE

\title{
To Document The Clinical Presentation and Outcome of Open Neural Tube Defect at Teaching Hospital, Dera Ghazi Khan
}

\author{
IQBAL AHMAD', MALIK LIAQAT ALI JALAL ${ }^{1}$, TEHMINA NAWAZ ${ }^{1}$ \\ SAMIA SAEED ${ }^{1}$, ARSLAN AHMED ${ }^{2}$, SAIMA KHADIM ${ }^{1}$ \\ ${ }^{1}$ Department of Neurosurgery, D.G. Khan Medical College \& Hospital, Dera Ghazi Khan - Pakistan. \\ ${ }^{2}$ King Edward Medical University, Lahore-Pakistan.
}

DOI: $10.36552 /$ pjns.v24i1.403

\begin{abstract}
Objectives: To study clinical presentation and to determine outcome of open Neural Tube Defects at our respected institution. We took a review of all cases of open neural tube defects seen at the Neurosurgery Unit of hospital in the last years to document their medical patterns, assess their neonatal outcome.
\end{abstract}

Materials and Methods: This retrospective study included 74 patients, admitted to the Department of Neurosurgery, D. G. Khan Medical College and Hospital, Dera Ghazi Khan. The procedure for history taking and clinical examination was completed to measure Folic Acid Intake in first trimester, ultra sound abdomen, pre-natal diagnosis, hydrocephalous, CSF leak from swelling, sphincter involvement, weakness of lower limb, previous baby affected, type \& location of open neural tube defects along the cranio-vertebral axis. Spine X-rays, neurosonograms, MRIs were carried out to find associated irregularities and complications if exist.

Results: Out of 74 children born with open neural tube defects, 9 (12\%) mothers received antenatal care only, 7 (9\%) get folic acid regularly. Prenatal diagnosis was made in 11 (14.8\%) mothers whose antenatal abdominal ultrasound was done. The most common type of myelomeningocele was lumbosacral 58 (79\%). Forty-four (59.4\%) babies have hydrocephalous while five babies were microcephaly. Increased risk of ruptured myelomeningocele was linked with vaginal delivery. Sphincter disturbance and limb paralysis was present in 35 (47\%) and $32(43.7 \%)$ of babies respectively. The mortality was in 12\% patients.

Conclusion: We suggest that efforts should be made in this respect to prenatal diagnosis of such lesions to get better neonatal outcome, also to prevent neural tube disorders through regular antenatal care including counseling, delivery planning, and multi-disciplinary postnatal management.

Keywords: Meningocele, Spina Bifida, Myelomeningocele.

\section{INTRODUCTION}

One of common congenital anomalies in infants is spinal dysraphism. Its incidence is $1-2 \%$ with some genetic factors. ${ }^{1,6}$ A large, geographically variation is also seen in such incidents.In spinal dysraphism, neural tube fails to close in midline posteriorly. Spina bifida Aperta includes following two entities: 1) Meningocele in which, there is congenital defect in vertebral arches with cystic distension of meningism no abnormality of nervous tissue. One third has some neurological defect. 2) Myelomeningocele in which, there is congenital defect in vertebral arches with cystic distension of meninges and structural or functional abnormalities of spinal cord or cauda equina. ${ }^{411,12}$ These defects develop early in pregnancy because the anterior neuropore closed at $25^{\text {th }}$ day of gestation and caudal neural pore closed on $28^{\text {th }}$ day. The main reason of spina bifida is unknown. It occurs 95\% in couples with negative family history. Deficiency of folic acid and also a deficiency of zinc have been projected as main cause. Identified aspects that are linked with high risk are motherly diabetes, 
excessive use of alcohol by the mother, ingestion of aminopterin, antenatal X-rays, infection to mother such as rubella and use of anticonvulsants in pregnancy are the other causes. Spina Bifida has two types. One is open spina bifida and other one is closed spina bifida, which arises when nervous tissues are exposed at birth through a bony defect. It has been found that due to deficiency of Folate (Vitamin B9) and Vitamin B12 in pregnancy increased high risk of NTDs. ${ }^{19}$

In general population, the open spina bifida cases contributes to significant number of proportion leading to disabilities. Antenatal diagnosis can be made early in pregnancy in ultrasound and by estimation of maternal serum and amniotic fluid alpha-fetoprotein. ${ }^{17}$ Even where the Option of pregnancy termination is not culturally acceptable, prenatal diagnosis allows room for anticipatory management, including determining best method regarding to delivery, while parents are psychologically prepared to accept an abnormal child. Immediate and long-term outcome are related to the size and site of the defects as well as the presence of complications or associated malformations in other organs such as the heart.

We undertook a review of all cases of open neural tube defects seen at the Neurosurgery Unit of hospital in the last years to document their medical patterns and assess their neonatal outcome.

\section{MATERIALS AND METHODS}

\section{Study Design}

Retrospective observational study. This study was conducted from August 2014 to February 2019.

\section{Inclusion/Exclusion Criteria}

Seventy-four patients with myelomeningocele, encephalocele or anencephaly formed the subjects of this study were analyzed retrospectively.

\section{Data Collection}

Prior written permission was attained from every patient attendant.

\section{Data Analysis}

Thereafter, a procedure for history taking and clinical examination was completed to measurefolic acid intake in first trimester, ultra sound abdomen, pre-natal diagnosis, hydrocephalous, CSF leak from swelling, sphincter involvement, weakness of lower limb, previous baby affected, type \& location of open neural tube defects along the cranio-vertebral axis. Spine Xrays, neurosonograms, MRIs were carried out to find associated irregularities and complications if exist.All the relevant information's transcribed to a predesigned proforma to ensure uniformity.

\section{RESULTS}

Our study was from August 2014 to February 2019 comprising 74 patients.

\section{Age Incidence}

Seventy three percent of which falls in the neonatal set of age.

\section{Gender Incidence}

Out of 74 (49 males and 25 females) with open neural tube defects.

\section{Clinical Features}

Nine (12\%) mothers received antenatal care only, 9\% had used folic acid regularly. Prenatal diagnosis was made in $14.8 \%$ mothers whose antenatal abdominal ultrasound was done. The most common type of myelomeningocele was lumbosacral (Table 1). Vaginal delivery was allied by the increased danger of ruptured myelomeningocele. Sphincter disturbance and limb weakness was present in $47 \%$ and $43 \%$ of babies respectively (Figure 5). 68\% of the patients had a myelomeningocele and $27 \%$ of them had a meningocele and 5\% encephalocele (Figure 1). Lumbosacral defect is present in 9 (79\%) patients.

\section{Types of Open NTDs}

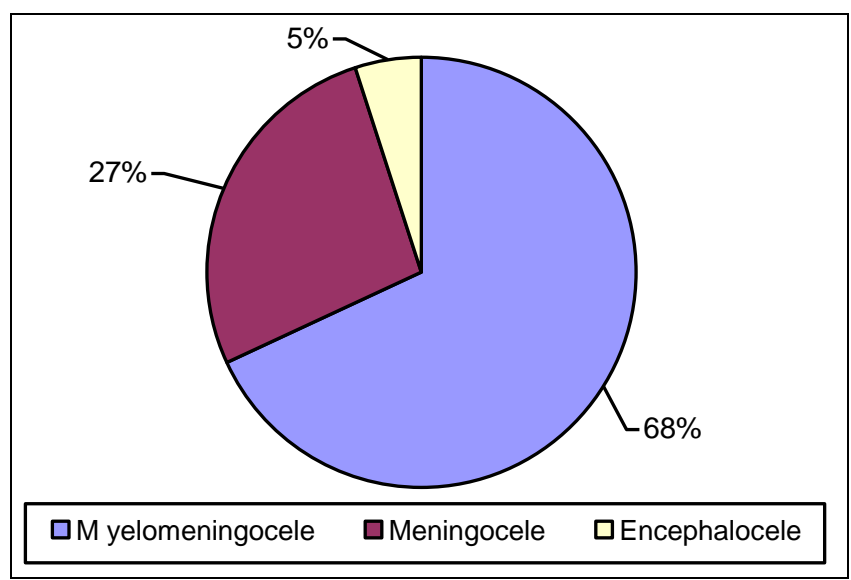

Fig. 1: Types of Open Neural Tube Defects. 
Forty four (59.4\%) babies have hydrocephalous, while five babies were microcephalic.

\section{Mortality}

Nine babies died representing mortality rate $12 \%$. Due to aspiration and sepsis.

Table 1: Location of Open Spina Bifida Defects among Three Regions of Spine.

\begin{tabular}{|l|c|c|}
\hline Location & Number & Percentage \\
\hline Cervical & 9 & $12 \%$ \\
\hline Thoracic & 6 & $9 \%$ \\
\hline Lumbosacral & 58 & $79 \%$ \\
\hline
\end{tabular}

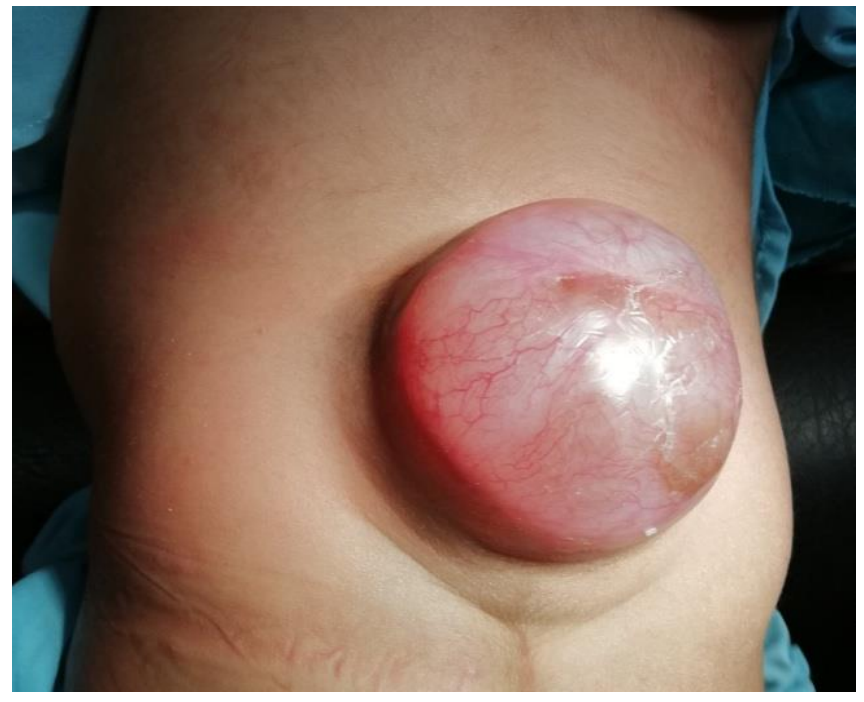

Fig. 3(A): Lumbosacral Myelomeningocele.

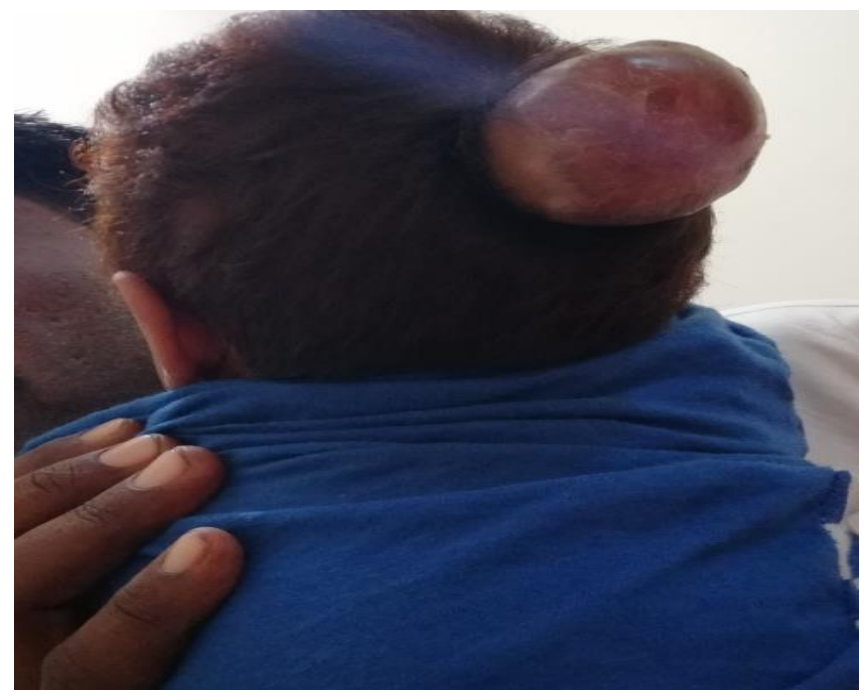

Fig. 3(B): Occipital Encephalocele.
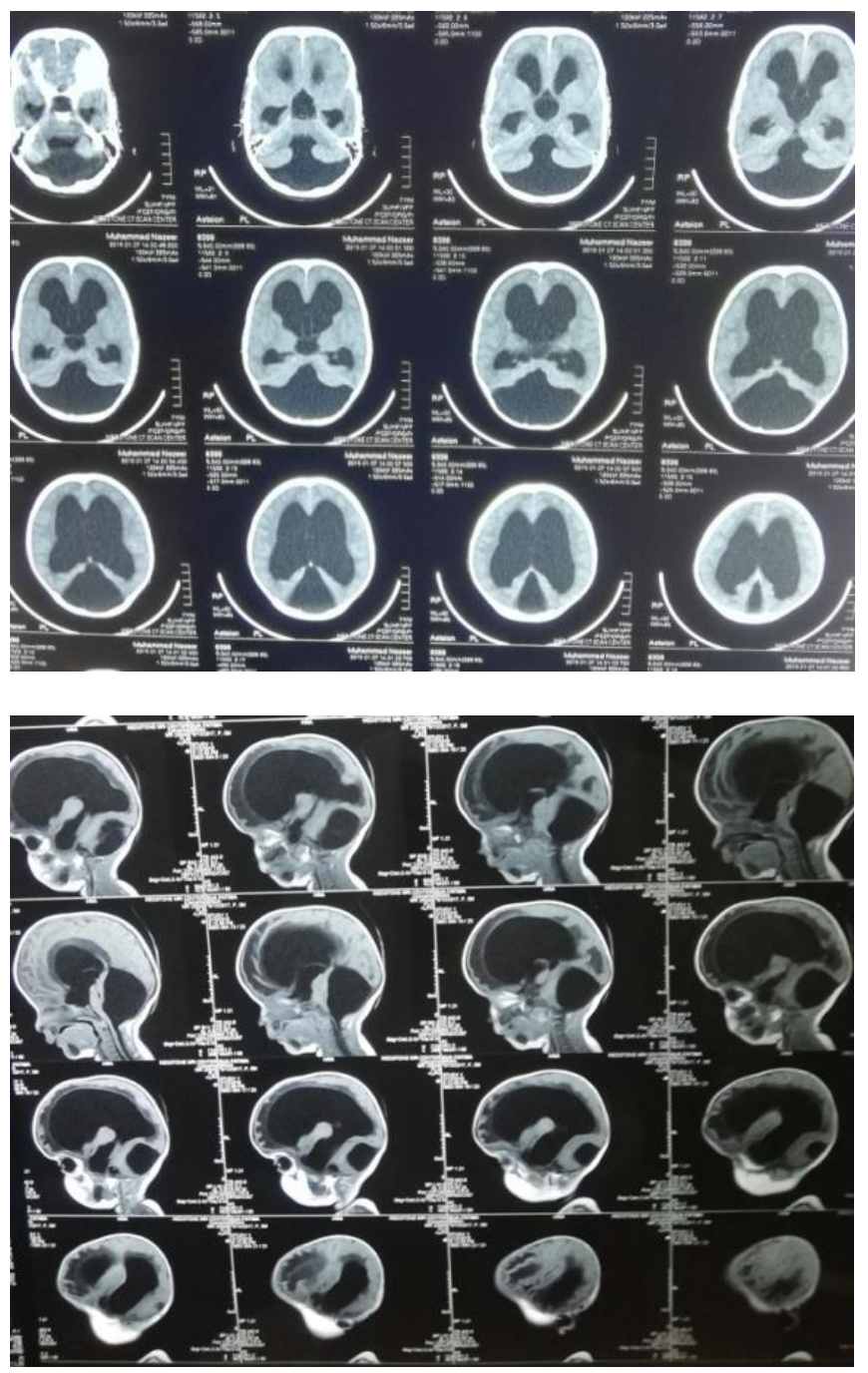

Fig. 4: Hydrocephalous associated with open neural tube defects.

\section{DISCUSSION}

There are two different syndromes associated with spinal dysraphism. One is spina bifida cystica that comprises myelomeningocele and characterized due to herniation of element by skin and a defect in bone. It is evident at the time of birth. Second one is Spina bifida occulta that consist a underlying neural disorder hidden by overlying skin. ${ }^{12,16,18}$

Myelomeningocele ${ }^{13}$ is the most common type of spina bifida which accounts for $68 \%$ of the cases. Genetically associated risk for this disease is reinforced by many researches. In this study, history given by parents evaluates the genetic relation. ${ }^{8}$ Deficiency of Folic acid is also a factor. Women with such affected background of pregnancy must take 4 $\mathrm{mg}$ of folic acid on a daily basis, start immediately as 


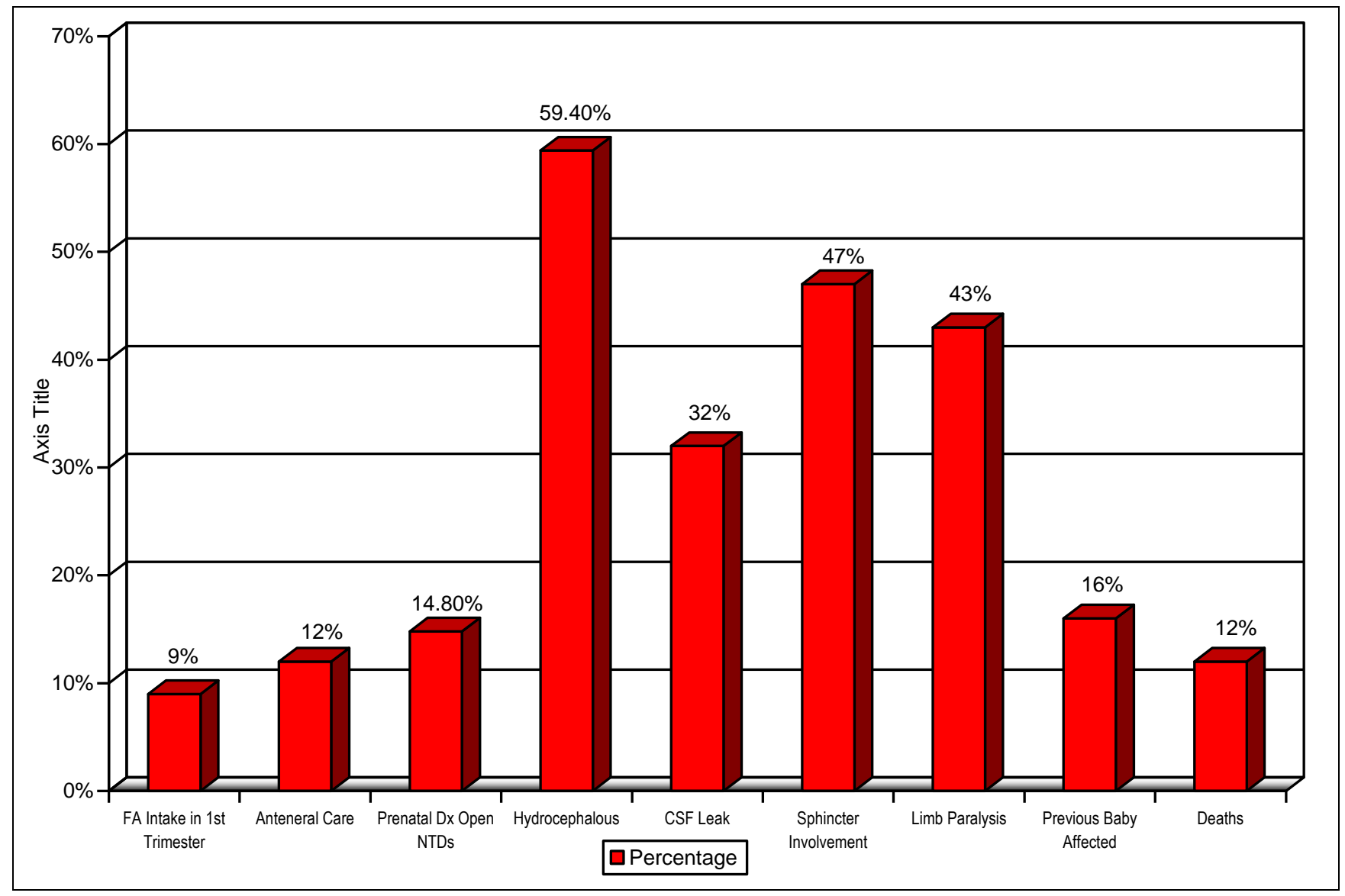

Fig. 5: Clinical Presentation and Outcome of Open Neural Tube Defect.

pregnancy start. In addition, socioeconomic status, exposure to radiation and maternal illness contributes to the condition.

Recent developments in the perinatal diagnosis of spina bifida abnormalities had made its diagnosis easier. Amniocentesis is recommended for families who are at risk to assess amniotic alpha-fetoprotein and acetyl-cholinesterase that are vital to separate open lesions from the skin.Ultrasound screening combined with Amniocentesis has shown more than 90\% accuracy. ${ }^{5,17}$

In most of the cases where spina bifida is not eliminated electively needs no treatment till after birth. And in order to prevent cerebrospinal fluid leak cesarean section is carried out. Open spina bifida patients has a strong association of hydrocephalous ranging from 45 to $80 .{ }^{2,10}$.

The utilization rate of abdominal ultrasound in pregnancy as seen in this study was low and few mothers who had an antenatal care (ANC) also had the abdominal ultrasound done. It is worthy of note that the diagnosis of congenital abnormality was made in only one of them despite the fact that this is a fairly common investigative tool that has the capacity of recognizing open NTDs in utero. It should however be noted that most of the mothers attended private and secondary public health institutions where they may find obstetricians. ${ }^{17}$

Only $9 \%$ mothers had taken folic acid regularly beginning from the pregnancy. Although, this does not necessarily imply a causal relationship between inadequate folate intake and NTD in our study, it can be postulated that the mothers of our patients were probably not exposed to adequate amounts of folic acid in early pregnancy and that this probably contributed to the development of NTD in their babies. ${ }^{19}$

Lumbo-sacral myelomeningocele as shown in this study is reportedly the most prevalent of open neural tube defects. The rarity of anencephaly as demonstrated in the present study where only one case was seen does not necessarily reflect the true incidence 
since a large proportion are aborted spontaneously. Rupture of myelomeningocele sac was seen in the babies delivered per vagina. This complication is linked with increased risk associated with meningitis and ventriculitis also delays surgical intervention. None of the babies delivered by caesarean section had a cerebrospinal fluid (CSF) leak. ${ }^{9}$

Where facilities are available and affordable, an elective Cesarean Section is reportedly associated with a better long-term neurological function in such patients. This may therefore be a better delivery option.

Hydrocephalus is said to be rare in upper thoracic and sacral lesions. ${ }^{2,10}$ Microcephaly was seen in the five babies. The presence of limb paralysis and sphincter dysfunction poses additional challenges in dealing with open spina bifida beyond the neonatal period.

\section{CONCLUSION}

We concluded that this disorder can be prevented by periconceptional and antenatal folic acid supplementation. All pregnant women should have two abdominal ultrasound examinations (1st and 2nd trimesters) during the period of antenatal care. While early diagnosis offers the opportunity for termination of a grossly abnormal conceptus, late antenatal diagnosis will enable prenatal counseling, planned cautious delivery and prompt and timely surgical intervention when indicated. Mothers who have had previous abnormal babies should be closely monitored in subsequent pregnancies. Since most pregnant women register very late for antenatal care and neural tube closure occurs at a time conception is hardly recognized, repetitive usage of folic acid by females of the child birth phase beginning from period of wed lock may be useful as a long-term measure. Meanwhile, public awareness of the need for early booking for antenatal care should be heightened. An extensive, multicenter, potential study may be necessary towards identification of the various risk issues linked through neural tube short comings and other major congenital malformations in our community. This will enable the evolution of a comprehensive package of preventive strategies for major congenital malformations. Some designated tertiary institutions should have human resources adequately trained to provide the immediate care required by these babies and others with major congenital malformations. All prenatally diagnosed cases of neural tube defect should be referred to such centers for delivery and subsequent baby care.

\section{REFERENCES}

1. Campbell LR, Dayton DH, Sohal GS. Neural tube defects: Areview of human and animal studies on the etiology of neuraltube defects. Teratology, 1986; 34: 171-187.

2. Elgamal EA. Natural history of hydrocephalus in children with spinal open neural tube defect. Surg Neurol Int. 2012; 3: 112.

3. Cama A, Tortori-Donati P, Piatelli GL, Fondelli MP, Andreussi L. Chiari complex in children-neuroradiological diagnosis, neurosurgical treatment and proposal of a new classification (312 cases). Eur $\mathrm{J}$ Pediatric Surg. 1995; 5 Suppl. 1: 35-38.

4. Tortori-Donati P, Rossi A, Cama A. Spinal dysraphism: a review of neuroradiological features with embryological correlations and proposal for a new classification. Neuroradiology, 2000; 42: 471-491.

5. Copp AJ, Stanier P, Greene ND. Neural tube defects: recentadvances, unsolved questions, and controversies. Lancet Neurol. 2013; 12: 799-810.

6. Hamamy H. Epidemiological profile of neural tube defects in Arab countries. Middle East Journal of Medical Genetics, 2014; 3: 1-10.

7. Bassuk AG, Kibar Z. Genetic basis of neural tube defects. SeminPediatrNeurol2009; 16: 101-110.

8. Copp AJ, Greene ND. Genetics and development of neural tube defects. J Pathol. 2010; 220: 217-230.

9. Aguilera S, Soothill P, Denbow M, Pople I. Prognosis of spina bifida in the era of prenatal diagnosis and outcome.

10. Coran Pediatric Surgery, 7th Edition, Chapter 128, Management of neural tube defects, hydrocephalus, Pages, 1674-1676.

11. Bruce A. Kaufman, Neural tube defects, Pediatric Clinics of North America, 2004; 51: 389-398.

12. Vademecum Pediatric Neurosurgery, Chapter 8, Spinal Dysraphism, Pages 143-149.

13. Mark S. Dias, MD; Michael Partington, MD, Embryology of Myelomeningocele and Anencephaly, Neurosurgical Focus, 2004; 16 (2).

14. Toriello HV, Higgins JV. Occurrence of neural tube defects among first-, second-, and third-degree relatives of probands: results of a United States study. Am J Medical Genetics, 1983; 15: 601-6.

15. P. G. SALUJA, The incidence of spina bifida occulta in a historic and a modern London population, J. Anat. 1988; 158: 91-93.

16. Kumar R. Singh S.N. Spinal Dysraphism: Trends in Northern India; J. Pediatric Neurosurgery; 2003; 38: 133-145.

17. Mohamed S, Ibrahim F, Kamil K, Satti SA. MeckelGruber syndrome: Antenatal diagnosis and ethical 
perspectives. Sudan J Paediatr. 2012; 12: 70-72.

18. Textbook of contemporary neurosurgery, Chapter 25 , Spinal and Cranial Dysraphism, Pages 338-340.

19. Hibbard BM. The role of folic acid in pregnancy. $\mathbf{J}$ Obstet Gynaecol Brit Commwlth. 1964; 71: 529-542.
20. Smithells RW, Shephard S, Schorah CJ et al. Possible prevention of neural-tube defects by periconceptional vitamin supplementation. Lancet 1980; i: 339-340. Sutcliffe M, Schorah CJ, Perry A et al. Prevention of neural tube defects Lancet. 1993; 342: 1174.

\section{Additional Information}

Disclosures: Authors report no conflict of interest.

Ethical Review Board Approval: The study was conformed to the ethicalreview board requirements.

Human Subjects: Consent was obtained by all patients/participants in this study.

Conflicts of Interest: In compliance with the ICMJE uniform disclosure form, all authors declare the following.

Financial Relationships: All authors have declared that they have no financial relationships at present or within the previous three years with any organizations that might have an interest in the submitted work.

Other Relationships: All authors have declared that there are no other relationships or activities that could appear to have influenced the submitted work.

Address for Correspondence: Dr. Iqbal Ahmad, FCPS (Neurosurgery) Assistant Professor Department of Neurosurgery, DGKMC \& Teaching Hospital, D G Khan - Pakistan Phone Numbers +92-3320784851Ｆacsimile Numbers +92-9260217Ｅ-mail address:driqbalahmad33@gmail.com

\begin{tabular}{|l|l|l|l|}
\hline \multicolumn{4}{|c|}{ AUTHORSHIP AND CONTRIBUTION DECLARATION } \\
\hline Sr.\# & Author's Full Name & Intellectual/Contribution to Paper in Terms of: & $\begin{array}{l}\text { Signature by the } \\
\text { author(s) }\end{array}$ \\
\hline 1. & Iqbal Ahmad Kharal & 1. Proposed topics and Basic Study Design, methodology. & 2. Data collection and calculations \\
\hline 2. & Malik Liaqat Ali Jalal & 3. Analysis of data. \\
\cline { 1 - 2 } 3. & Tehmina Nawaz & 4. Literature review and manuscript writing & 5. Paper writing \\
\hline 4. & Samia Saeed & 6. Literature review & \\
\hline 5. & Arslan Ahmad & Saima Khadim &
\end{tabular}

Date of Submission: 16-01-2020

Date of Revision: 06-03-2020

Date of Online Publishing: 31-03-2020

Date of Print: 31-03-2020 